\title{
Potential of Lunasin Orally-Administered in Comparison to Intraperitoneal Injection to Inhibit Colon Cancer Metastasis in Vivo
}

\author{
Vermont P. Dia, Elvira Gonzalez de Mejia \\ Department of Food Science and Human Nutrition, University of Illinois at Urbana-Champaign, Urbana, USA. \\ Email: edemejia@illinois.edu
}

Received April 27 $7^{\text {th }}, 2013$; revised May $31^{\text {st }}, 2013$; accepted June $8^{\text {th }}, 2013$

Copyright (C) 2013 Vermont P. Dia, Elvira Gonzalez de Mejia. This is an open access article distributed under the Creative Commons Attribution License, which permits unrestricted use, distribution, and reproduction in any medium, provided the original work is properly cited.

\begin{abstract}
Lunasin is a bioactive peptide originally isolated from soybean and has demonstrated chemopreventive and anti-cancer properties against skin, colon and breast cancers. The objective of the study was to evaluate the capability of intraperitoneally and orally-administered soybean-derived peptide lunasin to inhibit KM12L4 human colon cancer cell metastasis in a mouse model. Intraperitoneal (i.p.) injection of lunasin $(4 \mathrm{mg} / \mathrm{kg}$ bw/day) reduced the number of liver metastasis by $50 \%(\mathrm{P}=0.047)$ and the liver weight/body weight ratio by $23 \%(\mathrm{P}=0.039)$. Oral administration of lunasin reduced the number of liver metastasis by $56 \%(8 \mathrm{mg} / \mathrm{kg}$ bw/day, $\mathrm{P}=0.293)$ and $94 \%(20 \mathrm{mg} / \mathrm{kg}$ bw/day, $\mathrm{P}=0.247)$. Immunohistochemical staining of the liver-tissue section showed that lunasin at $20 \mathrm{mg} / \mathrm{kg}$ bw dose did not significantly reduce the expression of proliferating cell nuclear antigen, increased the expression of proapoptotic Bax by 2.7 -fold but also increased the expression of the antiapoptotic Bcl-2 by 3.8-fold. Regarding epigenetic markers, H3K18 was not significantly affected by either oral dose while H4K8 was dose dependently increased by 2.3 -fold $(\mathrm{P}=0.001,8 \mathrm{mg} / \mathrm{kg}$ bw) and 2.7-fold ( $\mathrm{P}<0.001,20 \mathrm{mg} / \mathrm{kg} \mathrm{bw})$. On the other hand, i.p. injection of lunasin reduced both histone acetylation markers significantly. The difference on the effects can be attributed to the different routes of administration used leading to digestion of lunasin when given by oral gavage. In conclusion, lunasin reduced colon cancer metastasis in vivo; however, more studies are needed to determine the oral dose of lunasin and prevent colon cancer metastasis.
\end{abstract}

Keywords: Lunasin; Colon Cancer; Metastasis; Apoptosis; Histones

\section{Introduction}

Colorectal cancer (CRC) ranks third as the most prevalent neoplasm worldwide with approximately $3.2 \mathrm{M}$ cases and is the second most prevalent cancer worldwide [1]. It encompasses a heterogeneous group of diseases with complex genetic and epigenetic alterations making molecular classification important in therapy-based decision making [2,3]. At early stage diagnosis, a curative management is achievable by surgical resection or by adjuvant or neo-adjuvant chemotherapy while late stage IV tumor-node-metastasis is a more advanced stage which is usually incurable [4]. Colorectal cancer metastasis which is characterized by the spread of the tumor to distant sites such as liver and lungs accounts for as much as $95 \%$ of CRC deaths. Metastasis is a very inefficient process characterized by dissociation of tumor cells from the primary tumor, invasion to the neighboring tissue, intra- vasation into the blood or lymphatic system, dissemination and extravasation and outgrowth at a secondary site. Lifestyle and dietary factors can increase the risk and progression of CRC such as smoking, red meat, alcohol consumption, increased total dietary calories and reduced physical activity. In order to prevent or reduce risk of developing CRC, calcium and nonsteroidal anti-inflammatory drugs intake has been suggested $[5,6]$. In addition, gene defects can contribute to over-all inherited predisposition to CRC [7].

Epidemiological studies have shown the inverse relationship between CRC risk and soybean consumption $[8,9]$. This protective effect of soybean against CRC can be attributed to biologically active components in soy including isoflavones, saponins, protease inhibitors and bioactive peptides. Lunasin is a 43 -amino acid bioactive peptide originally isolated from soybean. It contains uni- 
que amino acid sequences including the cell adhesion motif composed of arginine-glycine-aspartic acid residue followed by polyaspartic acid tail composed of 8 aspartic acid residues [10]. Studies showed that lunasin acted through epigenetic mechanism of action competing with different histone acetyltransferases, inhibiting histone acetylation and repressing the cell cycle progression [11-13]. Metastasis can be affected by different epigenetic mechanisms including DNA methylation, histone modifications and microRNA alterations and that diet can induce these epigenetic changes [14] and study showed that lunasin was able to inhibit acetylation of $\mathrm{H} 3$ and $\mathrm{H} 4$ histones [15]. We have also showed the capability of lunasin to promote apoptosis in different human colon cancer cells [16,17]. In addition, intraperitoneal injection of lunasin at a dose present in $25 \mathrm{~g}$ soy protein was able to inhibit CRC metastasis in vivo and potentiated the effect of the chemotherapeutic drug oxaliplatin [17]. However, the potential of orally administered lunasin on preventing the metastasis of CRC in vivo is not yet known. The objective of this study was to evaluate the capability of orally-administered in comparison to intraperitoneally-injected lunasin to inhibit KM12L4 human colon cancer cell metastasis in a mouse model.

\section{Materials and Methods}

\subsection{Materials}

Human colon cancer cells KM12L4 were obtained from Dr. Lee M. Ellis (MD Anderson Cancer Center, University of Texas).The metastatic KM12L4 cell line was established by injecting the parental cell line KM12C into the spleen of nude mice as previously reported [18]. Eagle's Minimum Essential Medium and $0.25 \%(\mathrm{w} / \mathrm{v})$ Trypsin- $0.53 \mathrm{mM}$ EDTA were purchased from American Type Culture Collection (Manassas, VA). Primary antibodies for PCNA, Bax, Bcl-2 and nucleolin were purchased from Santa Cruz Biotechnology (Santa Cruz, CA) while primary antibodies for p300, HDAC2, H3K18 and H4K8 were purchased from Abcam (Cambridge, MA). Immunohistochemical staining kit was purchased from Santa Cruz Biotechnology (Santa Cruz, CA). Luna$\sin (>95 \%$ purity) was isolated and purified from defatted soybean flour as previously reported [19].

\subsection{In Vivo Model of Colorectal Cancer Metastasis}

The protocol was approved by the Institute of Animal Care and Use Committee at the University of Illinois at Urbana-Champaign. Six to 8 weeks old mice were purchased from Harlan Laboratories and acclimated for one week and 1,000,000 KM12L4 colon cancer cells sus- pended in $50 \mu \mathrm{L}$ Hank's balanced salt solution were injected directly to the spleen of anesthetized mouse. In Spring 2011, mice were divided into 2 groups 4 days after cancer cell injection as follows: 1) control administered with PBS intraperitoneally as vehicle for 28 days $(\mathrm{n}=10)$; and 2) lunasin treated group at $4 \mathrm{mg} / \mathrm{kg}$ bw administered by intraperitoneal injection for 28 days $(n=9)$. In Summer 2012, mice were randomized into 3 groups 4 days after cancer cell injection as follows: 1) control administered with $100 \mu \mathrm{L}$ PBS by gavage as vehicle for 28 days after randomization $(\mathrm{n}=6) ; 2)$ lunasin treated group was gavaged with lunasin at $8 \mathrm{mg} / \mathrm{kg}$ bw daily suspended in $100 \mu \mathrm{L}$ PBS for 28 days after randomization $(\mathrm{n}=5)$; and 3) another set of mice were injected with $1,000,000$ KM12L4 colon cancer cells suspended in $50 \mu \mathrm{L}$ Hank's balanced salt solution after the completion of the first set and were given lunasin by oral gavage at $20 \mathrm{mg} / \mathrm{kg}$ bw daily for 28 days $(n=3)$. The experimental design for this study is shown in Figure 1. All groups received a standard AIN-93G powdered diet devoid of soy protein (Harlan Laboratories, Madison WI) along with the treatment. Mice were sacrificed by carbon dioxide asphyxia one day after 28 days of treatment. Total body weight and liver weight were determined during necropsy. The number of metastatic nodules on the liver was quantified. Liver tumor was fixed in $10 \%$ formalin buffered solution for $24 \mathrm{~h}$ prior to tissue processing and paraffin embedding for immunohistochemical analyses. Blood was collected by cardiac puncture immediately after asphyxia.

\subsection{Hematoxylin and Eosin Staining of Paraffin-Embedded Sections of Liver}

Liver CRC tumors were stained with hematoxylin and eosin (H and E) by standard method. Stained slides were visualized using Nanozoomer Digital Pathology (Olympus Hamamatsu, Bridgewater, NJ).

\subsection{Immunohistochemical Analysis}

Paraffin-embedded liver tumor tissue was cut at $5 \mu \mathrm{m}$ thickness and transfer to a slide prior to immunohistochemical (IHC) analyses. IHC for proliferating cell nuclear antigen (PCNA), Bax, Bcl-2, p300, histone deacetylase 2 (HDAC2), acetylated histone $\mathrm{H} 3$ at lysine 18 (H3K18) and acetylated histone $\mathrm{H} 4$ at lysine 8 (H4K8) was performed following manufacturer's protocol (Santa Cruz Biotechnology, CA). Stained slides were visualized using Nanozoomer Digital Pathology (Olympus Hamamatsu, Bridgewater, NJ). Intensity of staining was quantified using Teton machine (MediaCybernetics, Inc., Bethesda MD) equipped with Axio Vision analysis software (Carl Zeiss, Jena, Germany). 
(a)

Spleen Injection, $1 \times 10^{6} \mathrm{KM} 12 \mathrm{~L} 4$ cells athymic nude mice
Treatment ended

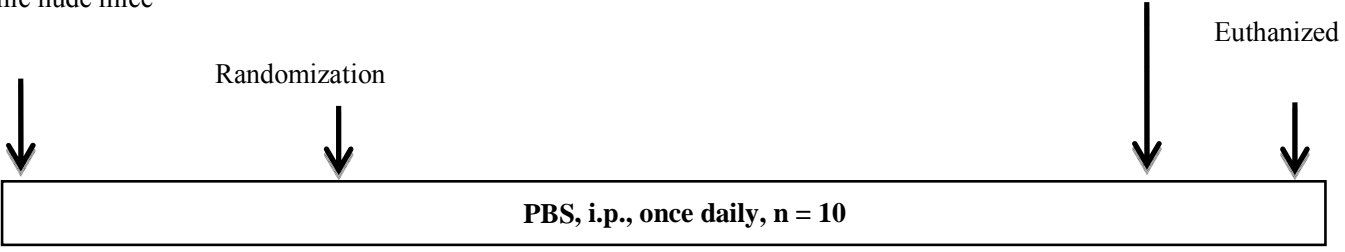

LUNASIN, 4 mg/kg bw, i.p., once daily, n = 9

$\begin{array}{llll}\text { D-4 } & \text { D0 } & \text { D28 } & \text { D29 }\end{array}$

(b) Spleen Injection,
$1 \times 10^{6} \mathrm{KM} 12 \mathrm{~L} 4$ cells
athymic nude mice

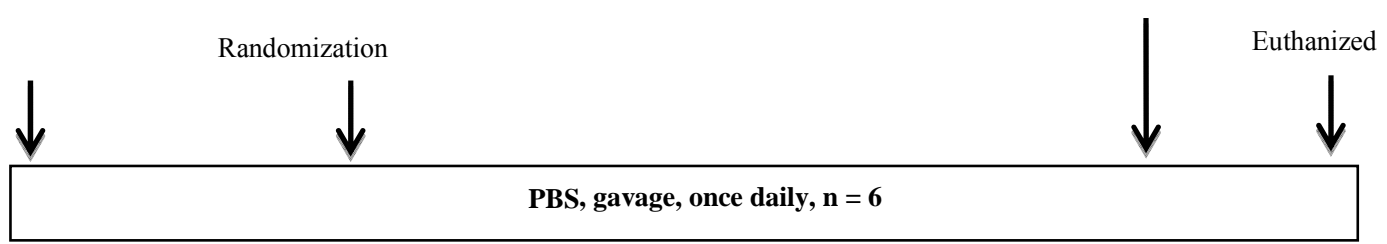

Treatment

ended

\section{LUNASIN, 8 mg/kg bw, gavage, once daily, $\mathrm{n}=5$}

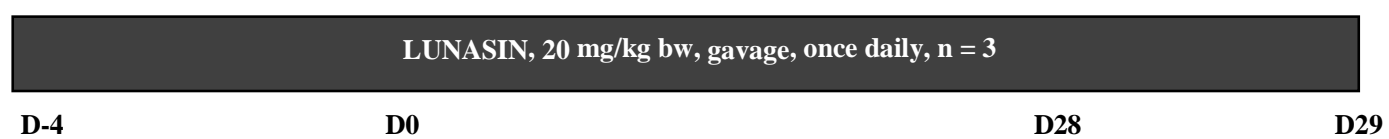

Figure 1. Schematic diagram for CRC model of liver metastasis and the potential of lunasin to inhibit the metastasis process. (a) In Spring 2011, 19 anesthetized mice were implanted with $1 \times 10^{6} \mathrm{KM1}$ L4 human colon cancer cells into the spleen. After 4 days, mice were randomized into two groups: PBS $(n=10)$ and lunasin at $4 \mathrm{mg} / \mathrm{kg}$ per day by intraperitoneal injection $(\mathrm{n}=$ 9). The treatment lasted for 28 days and 1 day after, mice were sacrificed by $\mathrm{CO}_{2}$ asphyxia. Number of metastatic nodules in the liver, liver weight and body weight were measured during necropsy. (b) In Summer 2012, 14 anesthetized mice were implanted with $1 \times 10^{6} \mathrm{KM} 12 \mathrm{~L} 4$ human colon cancer cells into the spleen. After 4 days, mice were randomized into three groups: PBS $(n=6)$, lunasin at $8 \mathrm{mg} / \mathrm{kg}$ per day by oral gavage $(\mathrm{n}=5)$ and lunasin at $20 \mathrm{mg} / \mathrm{kg}$ per day by oral gavage $(\mathrm{n}=3)$. The treatment lasted for 28 days and 1 day after, mice were sacrificed by $\mathrm{CO}_{2}$ asphyxia. Number of metastatic nodules in the liver, liver weight and body weight were measured during necropsy.

\subsection{Analysis of Histones in Blood by Western Blot}

Red blood cells were lysed using cell lysis solution $(3 \times$ volume of red blood cells) and incubated for $10 \mathrm{~min}$ at room temperature. The sample was centrifuged at $2000 \times$ $\mathrm{g}$ for $10 \mathrm{~min}$. The pellet was washed with cell lysis buffer three times after which the pellet was washed with 10 $\mathrm{mM}$ Tris- $\mathrm{HCl} \mathrm{pH} 7.4$ with $13 \mathrm{mM}$ EDTA. After centrifugation the pellet was resuspended in $100 \mu \mathrm{L}$ ice-cold water and sulfuric acid was added to a final concentration of $0.4 \mathrm{~N}$. After one hour incubation in ice, the mixture was centrifuged for $5 \mathrm{~min}$ at $12,000 \times \mathrm{g}$ at $4^{\circ} \mathrm{C}$. The supernatant was transferred to $1-\mathrm{mL}$ ice cold acetone and incubated at $-20^{\circ} \mathrm{C}$ overnight. After centrifugation for $5 \mathrm{~min}$ at $12,000 \times \mathrm{g}$ at $4^{\circ} \mathrm{C}$, the pellet was air-dried and resuspended in $50 \mu \mathrm{L}$ water. The protein concentration was determined by Protein DC Assay (Bio-Rad, Hercules, CA) and suspended in equal volume of reducing Laemmli buffer. Equal amount of proteins was loaded in 4\% - 20\% Tris- $\mathrm{HCl}$ ready gels (Biorad Laboratories, Hercules, CA, USA) for protein separation. The separated proteins were transferred to PVDF membrane and blocked with $5 \%$ nonfat dry milk in $0.1 \%$ Trisbuffered saline Tween 20 (TBST) for $1 \mathrm{~h}$ at $4^{\circ} \mathrm{C}$. After blocking, the membrane was washed with $0.1 \%$ TBST ( 5 times, 5 min each) and incubated with H3K18, H4K8 and nucleolin primary antibodies at $4^{\circ} \mathrm{C}$ overnight. The mem- 
brane was washed again and incubated with $\operatorname{IgG}$ horseradish peroxidase conjugate secondary antibody for $2-3 \mathrm{~h}$ at room temperature. After incubation and repeated washings, the expression of H3K18, H4K8 and nucleolin was visualized using chemiluminescent reagent (GE Healthcare, Buckinghamshire, UK). Analyses were done for three independent replicates.

\subsection{Statistical Analyses}

A PROC GLM and non-parametric Mann-Whitney test was used to test for statistical differences between groups. Significant differences were reported at $\mathrm{P}$ values $<0.05$.

\section{Results}

Figure 2 compares the effect of lunasin on the metastasis of KM12L4 colon cancer cells from the spleen to the liver of mouse. Intraperitoneal administration of lunasin resulted in the reduction of CRC liver metastasis by $50 \%$ compared to PBS group [P $=0.047$, Figure 2(a)] while the liver weight/body weight ratio was reduced by $23 \%$ $[P=0.039$, Figure 2(b) $]$. Oral administration of lunasin resulted in the reduction of the number of metastatic nodules in the liver of the mouse 28 days after treatment. PBS-treated group had $18 \pm 9$ (average \pm SEM, 100\%) liver metastatic nodules, the number of metastatic nodules was reduced $56 \%(8 \pm 2, \mathrm{P}=0.293)$ and $94 \%(1 \pm 0$, $\mathrm{P}=0.247$ ) in groups treated with $8 \mathrm{mg}$ lunasin $/ \mathrm{kg}$ bw/day and $20 \mathrm{mg}$ lunasin/ $\mathrm{kg}$ bw/day, respectively [Figure 2(c)]. Oral gavage of lunasin also resulted in a not statistically significant reduction of liver weight-body weight ratio from 0.11 (100\%, PBS-group) to 0.05 (42\% reduction, 8 $\mathrm{mg} / \mathrm{kg}$ bw/day-group) and 0.06 (41\% reduction, $20 \mathrm{mg} /$ $\mathrm{kg}$ bw/day-group) as shown in Figure 2(d). Representative liver pictures from mice in each group are shown as an inset in Figures 2(a) and (c) showing less number of tumor metastatic nodules in mice treated with lunasin compared to PBS-treated group.

Hematoxylin and eosin staining [Figure 3(a)] of paraffin-embedded liver tissues showed the development of tumor mass in PBS-group as well as mice treated with 8 $\mathrm{mg}$ lunasin/kg bw/day. On the other hand, development of tumor mass in mice treated with $20 \mathrm{mg}$ lunasin $/ \mathrm{kg}$ bw/day was not evident rather a hepatic hyperplasia was observed. Expression of proliferating cell nuclear antigen [PCNA, Figure 3(b)] was reduced $11.3 \%$ and $37.2 \%$ by $8 \mathrm{mg} / \mathrm{kg}$ bw/day $(\mathrm{P}=0.245)$ and $20 \mathrm{mg} / \mathrm{kg}$ bw/day $(\mathrm{P}=$ 0.122 ), respectively, short of statistical difference with the PBS group.

Evaluation of apoptotic markers showed that proapoptotic Bax was increased by 1.3 -fold in liver-tissue tumor of mice treated with $8 \mathrm{mg} / \mathrm{kg}$ bw/day lunasin though the $\mathrm{P}$-value was not significant $(\mathrm{P}=0.065)$. Anti-

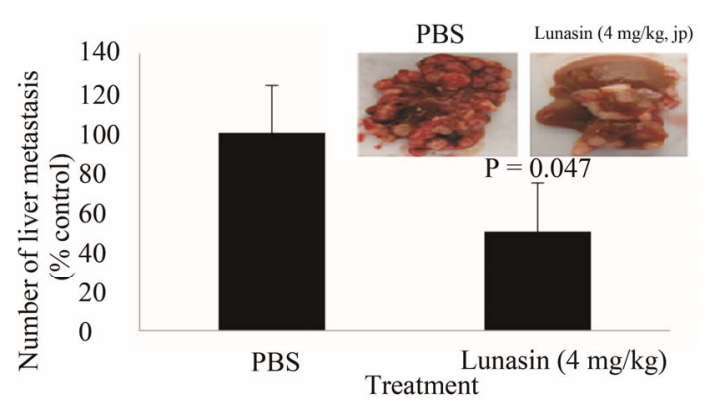

(a)

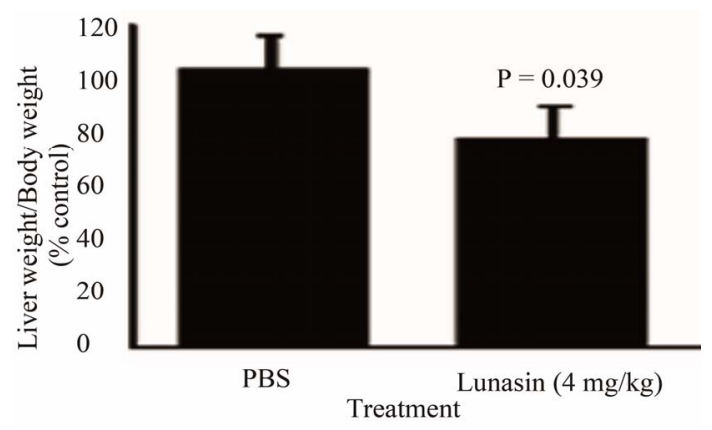

(b)

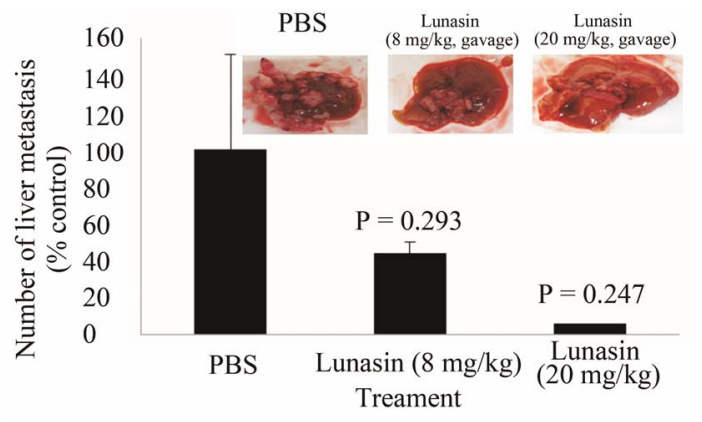

(c)

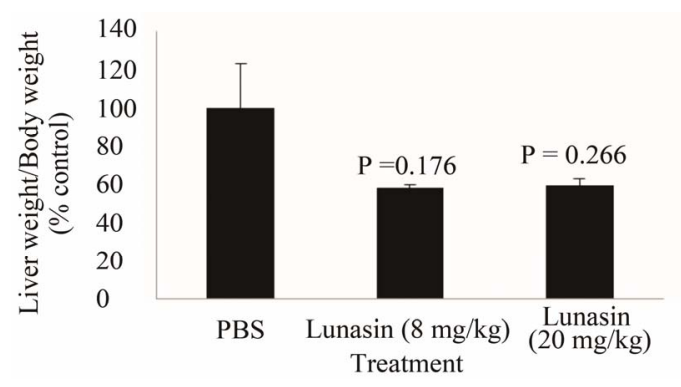

(d)

Figure 2. Mode of administration affected the ability of the bioactive peptide lunasin to inhibit the metastasis of KM12L4 human colon cancer cells from the spleen to liver of nude mice. Intraperitoneal injection of lunasin $(4 \mathrm{mg} / \mathrm{kg} \mathrm{bw}, \mathrm{n}=9$ ) significantly reduced the mean number of liver metastasis (a) and the mean liver weight/body weight ratio (b) when compared to PBS group $(\mathrm{n}=10)$ (Reference 17). Oral administration of lunasin at $8 \mathrm{mg} / \mathrm{kg} \mathrm{bw}(\mathrm{n}=5)$ and $20 \mathrm{mg} / \mathrm{kg}$ body weight $(n=3)$ did not significantly reduce the number of liver metastasis (c) and liver weight/body weight ratio (d) when compared to PBS group $(n=6)$. 


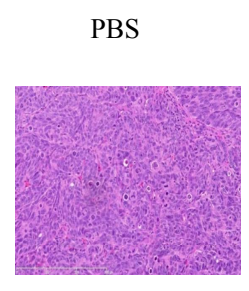

$\overline{300 \mu \mathrm{m}}$

PBS
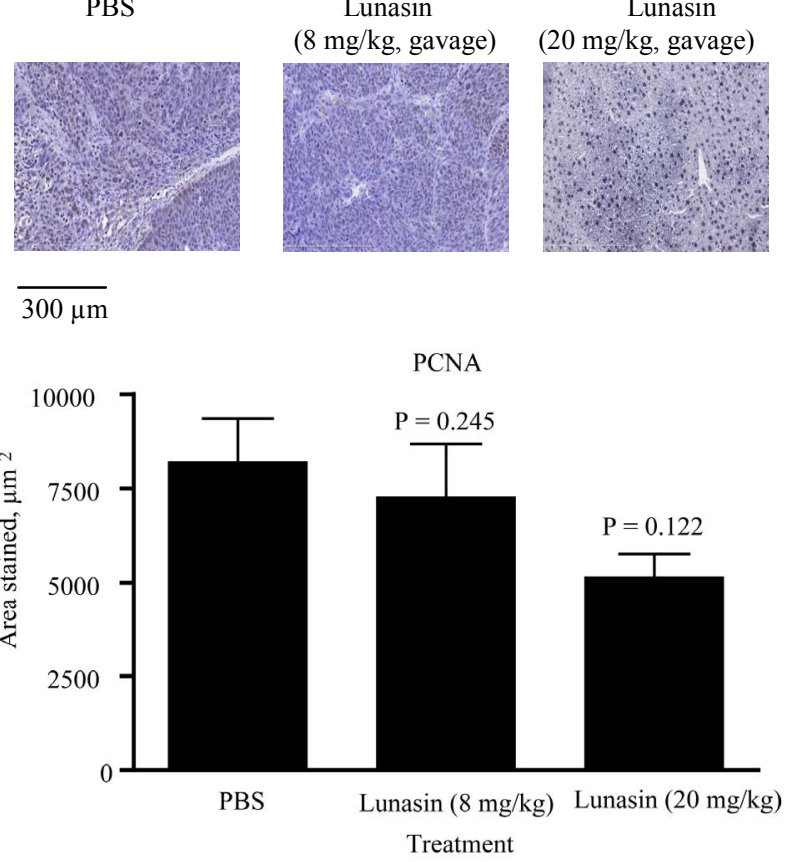

(b)

Figure 3. (a) Hematoxylin and eosin staining showed that lunasin modified the liver-tumor tissue derived from KM12L4 cells morphology. At $20 \mathrm{mg} / \mathrm{kg}$ bw given by oral gavage $(\mathrm{n}=$ 3) modified the liver morphology of mice showing hepatic hyperplasia while sections from PBS $(n=6)$ and lunasin (8 $\mathrm{mg} / \mathrm{kg}$ bw, $\mathrm{n}=5$ ) showed tumor morphology. (b) Lunasin did not significantly reduce the expression of PCNA in the liver-tumor tissue compared to PBS $(P=0.245$ for $8 \mathrm{mg} / \mathrm{kg}$ bw dose) and on non-tumor liver tissue ( $P=0.122$ for 20 $\mathrm{mg} / \mathrm{kg}$ bw dose). The expression of PCNA was evaluated in non-tumor liver tissue of mice $(20 \mathrm{mg} / \mathrm{kg} \mathrm{bw})$ due to absence of tumor metastasis. Based on the peroxidase staining assay the color produced was brown. All tissue samples from mice were analyzed and 5 independent fields were randomly selected per slide and compared to PBS (as determined by Mann-Whitney analysis).

apoptotic Bcl-2 was also reduced by lunasin treatment ( 8 $\mathrm{mg} / \mathrm{kg}$ bw/day) by 1.3-fold in a non-significant manner $(\mathrm{P}=0.368)$. Analysis of these markers in liver-tissue (non-tumorous) of mice treated with $20 \mathrm{mg} / \mathrm{kg}$ bw/day showed that Bax was significantly increased by 2.7 -fold $(\mathrm{P}=0.001)$ with a concomitant increase in Bcl-2 by $3.8-$ fold $(\mathrm{P}<0.001)$ [Figures 4(a) and (b)].
PBS

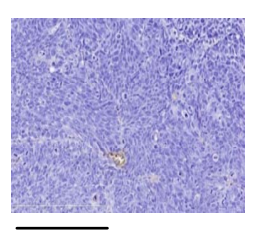

$\overline{300 \mu \mathrm{m}}$

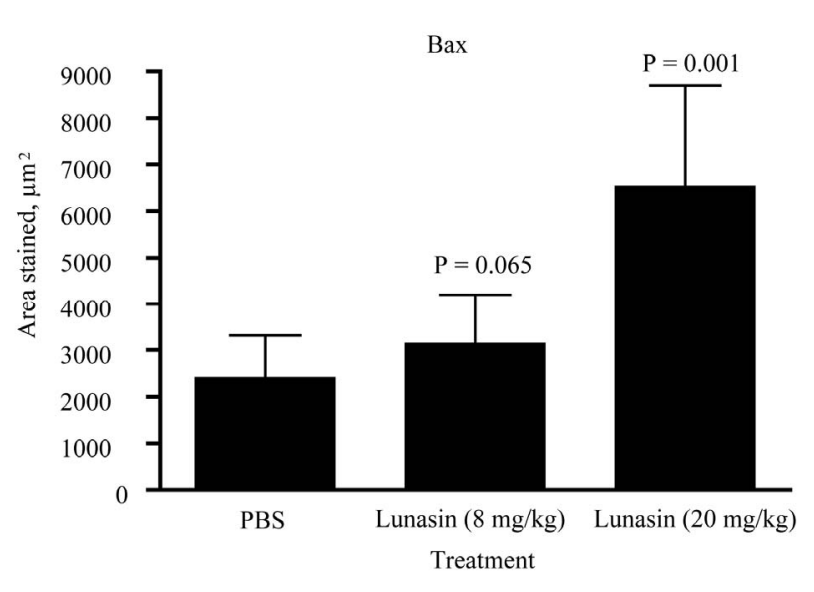

(a)

(20 mg/kg, gavage)

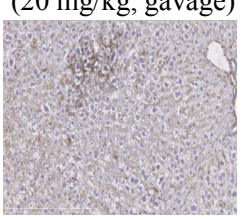

. .

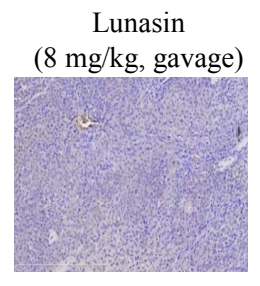

PBS

Lunasin (8 mg/kg, gavage)

Lunasin (20 mg/kg, gavage)
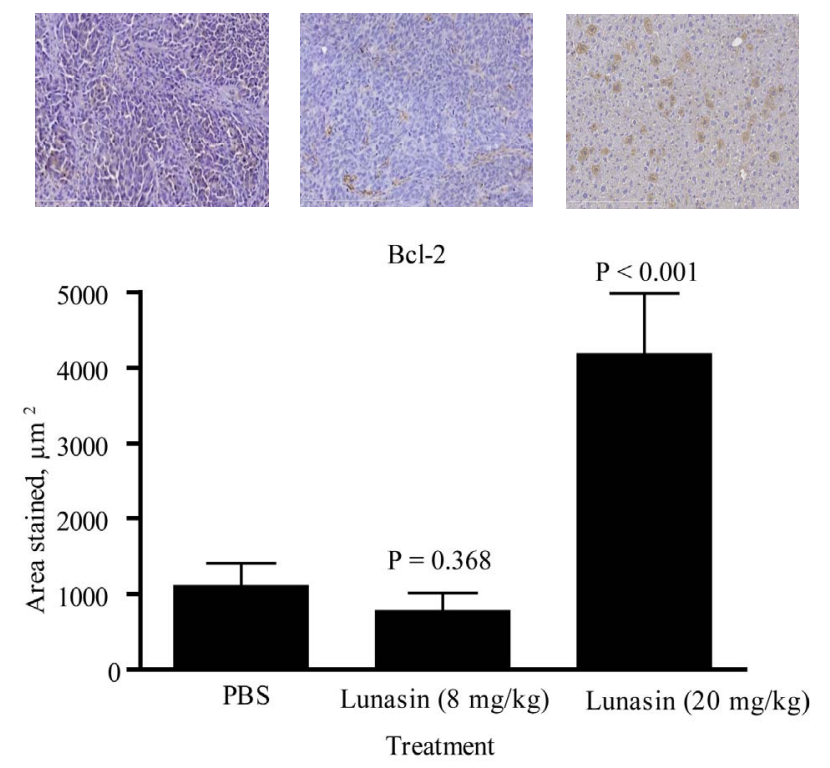

(b)

Figure 4. Effect of lunasin on the expression of apoptotic markers on liver tissue of mice injected with KM12L4 human colon cancer cells in the spleen. Lunasin at $8 \mathrm{mg} / \mathrm{kg} \mathrm{bw}$ given by oral gavage did not significantly affect the expressions of apoptotic proteins Bax (a), $\mathrm{P}=\mathbf{0 . 0 6 5}$ ) and Bcl-2 (b), $P=0.368$ ) in liver-tissue section of mice. At $20 \mathrm{mg} / \mathrm{kg} \mathrm{bw}$, both markers were increased in nontumor liver tissue. Based on the peroxidase staining assay the color produced was brown. All tissue samples from mice were analyzed and 5 independent fields were randomly selected per slide. 
Earlier studies on the biological activity of lunasin focused on its capability to alter histone acetylation/deacetylation process. The expression of H3K18 and acety- lated H4K8 is shown in Figures 5 and 6. Expressions of H3K18 and H4K8 were reduced significantly by intraperitoneal injection of lunasin at $4 \mathrm{mg} / \mathrm{kg}$ bw/day when
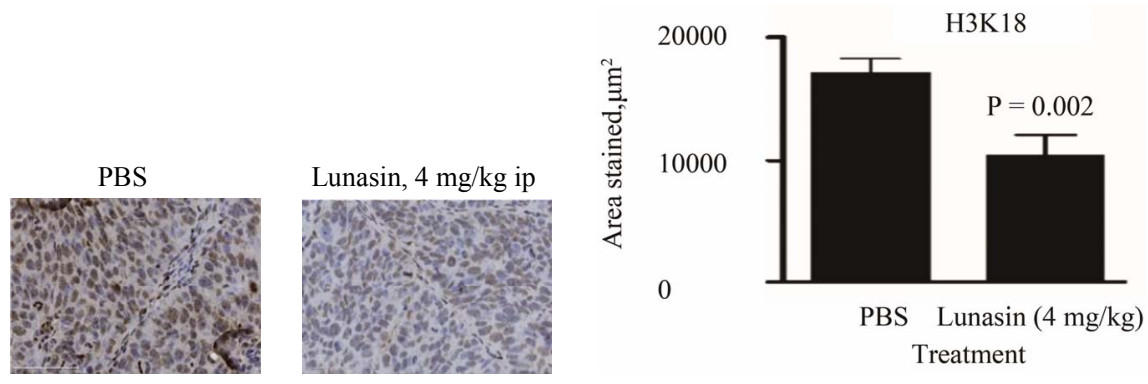

(a)
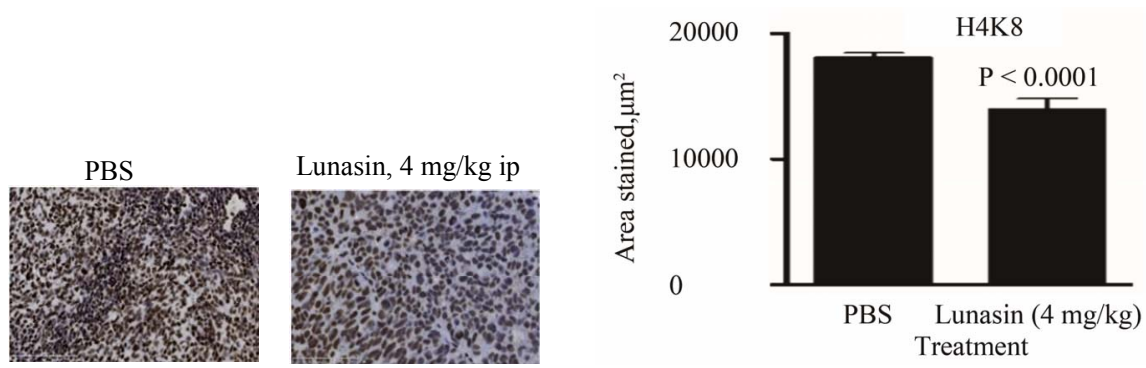

(b)
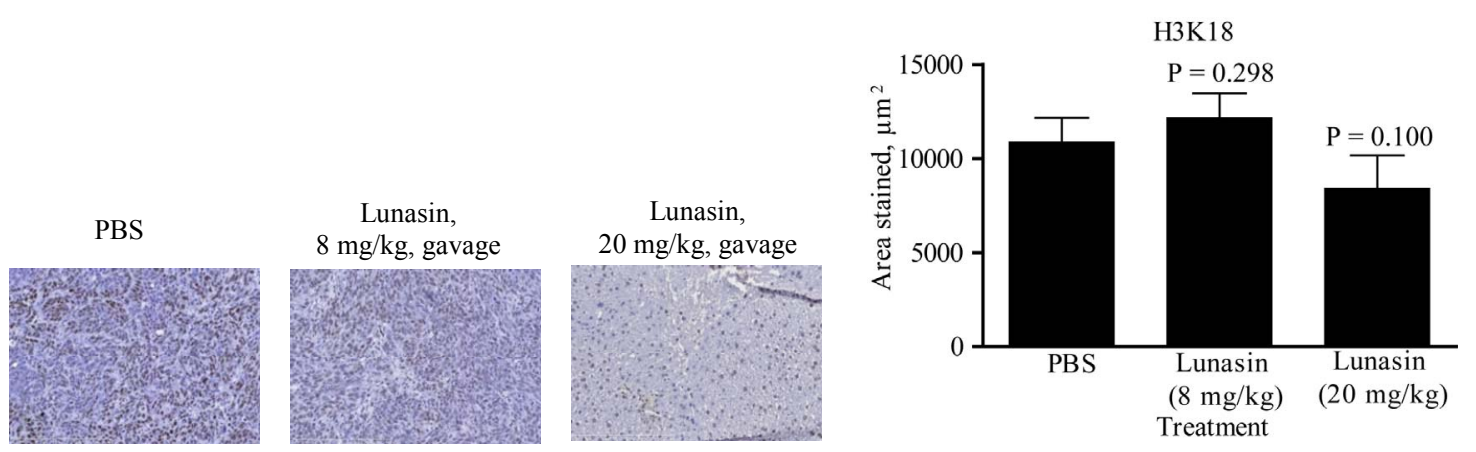

(c)

PBS

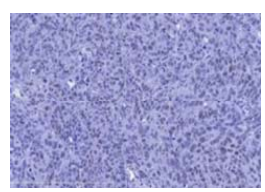

Lunasin, $8 \mathrm{mg} / \mathrm{kg}$, gavage

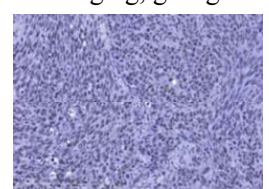

Lunasin,

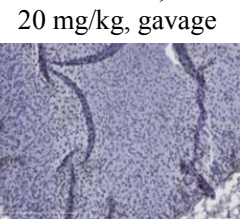

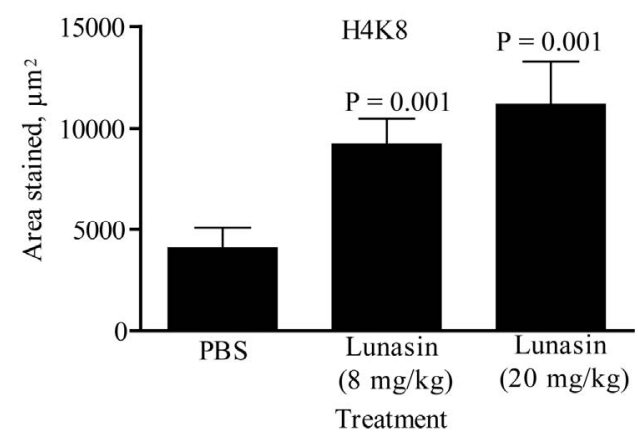

(d)

Figure 5. Intraperitoneal injection of lunasin at $4 \mathrm{mg} / \mathrm{kg}$ bw for 28 days modified the expression of epigenetic markers in liver-tissue section of nude mice injected with KM12L4 human colon cancer cells in the spleen. Lunasin (4 mg/kg bw, i.p. injection) reduced the expression of $(\mathrm{A}) \mathrm{H} 3 \mathrm{~K} 18(\mathrm{P}=\mathbf{0 . 0 0 2})$, (B) $\mathrm{H} 4 \mathrm{K8}(\mathrm{P}<\mathbf{0 . 0 0 0 1})$. Lunasin given by oral gavage did not significantly affect the expressions of H3K18 (C, P > 0.05) but significantly increased the expression of H4K8 (D, P = 0.001 for 8 $\mathrm{mg} / \mathrm{kg} \mathrm{bw}$ and $P=0.001$ for $20 \mathrm{mg} / \mathrm{kg} \mathrm{bw}$ ) in liver-tissue section of mice. Based on the peroxidase staining assay the color produced was brown. All tissue samples from mice were analyzed and 5 independent fields were randomly selected per slide. 

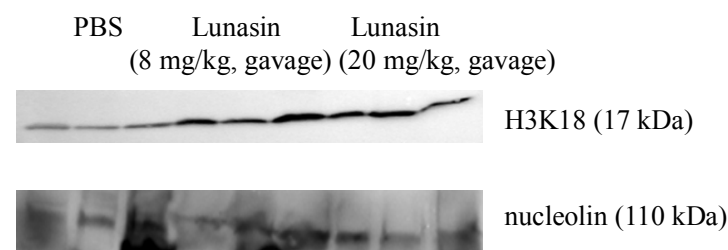

(a)
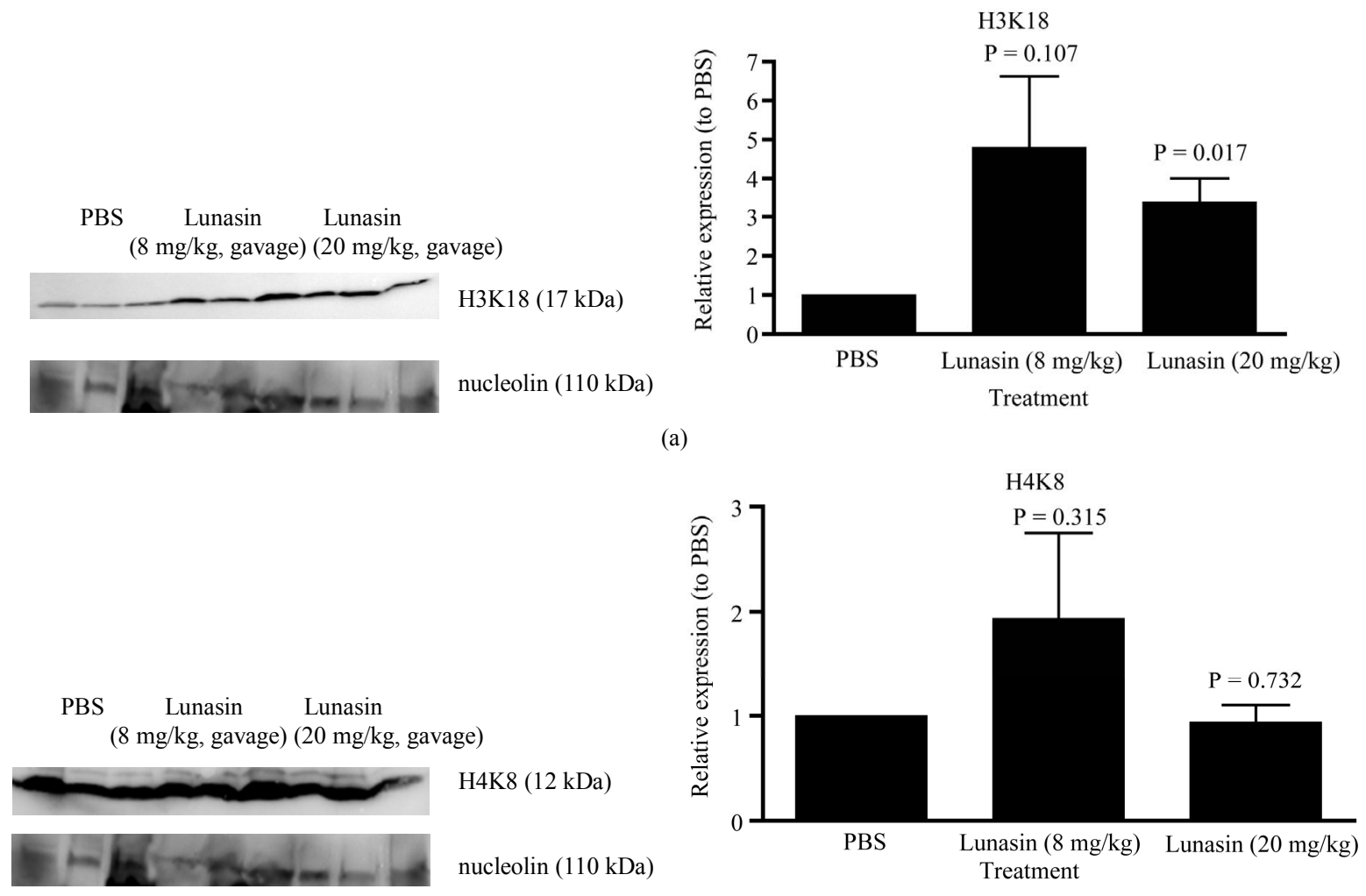

(b)

Figure 6. Lunasin at $20 \mathrm{mg} / \mathrm{kg}$ bw significantly increase the expression of H3K18 (a) but not H4K8 (b) in red blood cells of mice harvested by acid extraction and acetone precipitation. Histones were extracted from red blood cells of three mice per group (n=3).

compared to PBS-treated group as depicted in Figure 5(a) $(\mathrm{P}=0.002)$ and Figure 5(b) $(\mathrm{P}<0.0001)$, respectively. This is concurrent with the reduced expression of the enzyme p300 and unaffected expression of HDAC2 in liver-tissue tumor section of mice treated with lunasin given intraperitoneally when compared to PBS group (data not shown). On the other hand, expression of H3K18 was not significantly affected by orally-administered lunasin treatment in the liver-tissue tumor of mice [Figure 5(c)] while the expression of H4K8 was significantly increased by oral lunasin administration by 2.3 fold $(8 \mathrm{mg} / \mathrm{kg}$ bw/day, $\mathrm{P}=0.001)$ and by 2.7 -fold $(20$ $\mathrm{mg} / \mathrm{kg} \mathrm{bw} /$ day, $\mathrm{P}=0.001$ ) [Figure 5(d)]. Analysis of these markers on the blood of mice by acid extraction and acetone precipitation showed that protein expression of both markers was increased in lunasin-treated groups as compared to PBS group; however the increase was not statistically significant $(\mathrm{P}>0.05)$ except for H3K18 in 20 $\mathrm{mg} / \mathrm{kg}$ bw/day (3.3-fold, $\mathrm{P}=0.017$ ) as shown in Figures 6(a) and (b).

\section{Discussion}

The most frequent site of metastasis for CRC is the liver. There are few therapeutic options to treat metastatic CRC making the 5-year survival rate only $10 \%$ [20] hence the need for compounds that can prevent or delay the onset of CRC metastasis. Previous studies have shown the capability of lunasin to prevent the process of carcinogenesis in different in vivo models of cancer including skin cancer [21], breast cancer [22,23] and colon [17]. Our previous study showed that intraperitoneal injection of lunasin at a dose found in $25 \mathrm{~g}$ of soybean was able to inhibit CRC liver metastasis in vivo and potentiated the effect of oxaliplatin [17]. In this study, we compared the efficacy of orally-administered lunasin to our previous intraperitoneal study in preventing the outgrowth of CRC metastasis from the spleen to the liver of mouse. Our results showed that oral gavage of lunasin was able to reduce the number of liver metastasis in mice however the trend was not significant. This is in contrast to what we observed on the ability of intraperitoneally administered lunasin to inhibit CRC metastasis. The representative liver pictures from each group also demonstrated that livers from mice treated with lunasin presented lesser number of tumor nodules [as inserts in Figures 2(a) and (c)], this is then supported by the ratio of liver weight to body weight [Figures 2(b) and (d)]. H and E staining demonstrated the architecture of the liver tissue 
that developed hepatic tumor nodules in the PBS group as well as mice that received $8 \mathrm{mg}$ lunasin $/ \mathrm{kg}$ bw/day (oral gavage). While mice that received $20 \mathrm{mg}$ lunasin $/ \mathrm{kg}$ bw/day (oral gavage) did not show characteristics of liver tumor instead a hepatic hyperplasia was observed. This result suggests that oral ingestion of lunasin at $20 \mathrm{mg} / \mathrm{kg}$ bw/day can be helpful in preventing the formation of liver metastasis from CRC.

Orally administered lunasin was not able to statisticcally reduce the expression of PCNA, a protein important in the proliferation of cancer cells. This observation is in contrast from our previous study showing the capability of intraperitoneally-administered lunasin to reduce PCNA expression by $32 \%$ [17]. Reduction in PCNA expression has been closely linked with reduced aggressiveness and growth of tumor as its expression is elevated during the $\mathrm{S}$ phase of the cell cycle to promote cell cycle progression [24]. Moreover, tumor cells, regardless of their origins, express higher levels of PCNA $[25,26]$ and PCNA gene deregulation and post-translational modifications are hallmarks of malignant cells [27]. Our results show that oral administration of lunasin cannot modify the expression of PCNA in liver-tumor tissue in vivo thereby suggesting that it cannot reduce the proliferation of livertumor metastasis. This is supported by the lack of statistical difference in the expression of apoptotic markers in liver-tumor tissue of mice treated with $8 \mathrm{mg} / \mathrm{kg}$ bw/day lunasin when compared to PBS. This effect was also observed in our previous study showing that intraperitoneally-administered lunasin was not able to significantly affect the expressions of Bax and Bcl-2 [17]. On the other hand, these markers were both increased in the nontumorous liver tissue of mice treated with $20 \mathrm{mg}$ lunasin $/ \mathrm{kg}$ bw. The increased expressions of these apoptotic markers with opposing apoptotic effects can be explained by the measurement of these markers in normal liver tissue instead from liver-tumor tissue. This observation has shown before in liver tissue of patients suffering from hepatocellular carcinoma that the normal liver tissue counterpart has an elevated expression of Bax and $\mathrm{Bcl}-2$ when compared to carcinoma tissues [28].

Initial studies on the biological activity of the peptide lunasin showed the capability of lunasin to alter gene expression through epigenetic mechanism by altering the histone acetylation/deacetylation process. The proposed mechanism is that lunasin selectively kills cells that are being transformed or newly transformed (by chemical carcinogens and/or viral oncogenes) thereby inhibiting histone acetylation and acting like a tumor suppressor [29]. The expressions of H3K18 and H4K8 in liver-tumor tissue were significantly reduced by intraperitoneal administration of lunasin. On the other hand, lunasin given by oral gavage did not affect the expression of
H3K18 $(\mathrm{P}>0.05)$ while dose-dependently increased the expression of H4K8. These differential effects of lunasin on histone modifications can be attributed to the route of administration used in the study. In intraperitoneallyadministered lunasin, the whole lunasin molecule circulates in the blood of mice which resulted in the inhibition of the activity of the p300 enzyme leading to downregulation of acetylation of $\mathrm{H} 3$ and $\mathrm{H} 4$ histones at lysine 18 and lysine 8 positions, respectively. On the other hand, lunasin when given orally was digested leading to production of peptides that may not have the ability to inhibit p300 enzyme thereby leading to increase of acetylation of $\mathrm{H} 4$ histone at lysine 8 position. Bioavailability study in humans showed that different peptides corresponding to lunasin sequences were found in plasma of young men that were fed with $50 \mathrm{~g}$ of soy protein [30]. These peptides may have different bioactive properties than intact lunasin thereby leading to a different histone modification effects. Previous studies on the capability of bioactive compounds also showed differential effects on histone modifications. For instance, garcinol resulted in a strong reduction in acetylation of $\mathrm{H} 3 \mathrm{~K} 18$ while increasing the expression of acetylated H4K16 and trimethylated H4K20 in vitro [31]. Histone modifications are inherited as epigenetic variations and are linked to gene activation or silencing. For instance, acetylation of histone proteins, particularly $\mathrm{H} 3$ and $\mathrm{H} 4$, is thought to lead to a relaxed chromatin structure and, therefore an enhanced rate of transcription [32]. Increase in the acetylation of histones can then lead to an increase in transcripttion of tumor metastasis genes that can be epigenetically regulated. For instance, E-cadherin, a protein that controls the epithelial-to-mesenchymal process can be epigenetically controlled through histone acetyl transferase enzyme p300 and transcription factor HNF3 [33,34]. Reduced expression of E-cadherin is commonly observed in cancers with weak cell-cell adhesion and higher invasiveness property [35] and that higher expression of E-cadherin was associated with lower occurrence of extrahepatic metastases after resection of liver metastases [36]. Hernandez-Ledesma et al. [15] showed that lunasin treatment resulted in the abrogation of $\mathrm{H} 4$ acetylation promoted by PCAF and the expression of $\mathrm{H} 4 \mathrm{~K} 8$ was reduced by $17 \%$ in MDA-MB-231 breast cancer cells. The same observation was made in the capability of lunasin to prevent acetylation of histones $\mathrm{H} 3$ and $\mathrm{H} 4$ promoted by p300 and PCAF enzymes $[12,13]$. This reduction in histone acetylation was in agreement on what we observed in the expressions of H3K18 and H4K8 in liver tissue of mice that received lunasin by intraperitoneal injection.

In summary, we compared the potential of intraperito- 
neally- and orally-administered lunasin to inhibit colon cancer liver metastasis in an in vivo model of CRC metastasis. We found that when given by intraperitoneal injection, lunasin was able to inhibit CRC metastasis significantly; while lunasin given by oral gavage ( 8 $\mathrm{mg} / \mathrm{kg}$ bw/day) did not show significant difference from the control group. The difference in the observed results can be explained by the route of administration used in the studies. Given the fact that lunasin is bioavailable [30], the amount of intact lunasin left after digestion was not enough to prevent CRC metastasis from the spleen to the liver. On the other hand, when given at $20 \mathrm{mg} / \mathrm{kg}$ bw/day, liver of mice from this group showed very low tumor burden but the number of animals in this group was small and not able to attain the power needed to get statistically significant results.

The results of the present study indicate that lunasin reduced colon cancer metastasis in vivo. More studies are needed to determine the oral dose of pure lunasin and prevent colon cancer metastasis.

\section{Acknowledgements}

We would like to thank Dr. Lee M. Ellis of the MD Anderson Cancer Research Center for providing the KM12L4 colon cancer cells; Guadalupe Garcia for assistance with the animal study. This work was supported by the USDA Cooperative State Research, Education and Extension Service (CSREES), AG 2010-34505-15767.

\section{REFERENCES}

[1] F. Bray, J. S. Ren, E. Masuyer and J. Ferlay, "Global Estimates of Cancer Prevalence for 27 Sites in the Adult Population in 2008," International Journal of Cancer, Vol. 132, No. 5, 2013, pp. 1133-1145. doi:10.1002/ijc. 27711

[2] Y. D. Benoit, K. B. Laursen, M. S. Witherspoon, S. M. Lipkin and L. J. Gudas, "Inhibition of PRC2 Histone Methyltransferase Activity Increases TRAIL-Mediated Apoptosis Sensitivity in Human Colon Cancer Cells," Journal of Cellular Physiology, Vol. 228, No. 4, 2013, pp. 764772. doi:10.1002/jcp. 24224

[3] R. Wang, C. V. Lohr, K. Fischer, W. M. Dashwood, J. A. Greenwood, E. Ho, D. E. Williams, H. Ashtrokab, M. R. Dashwood and R. H. Dashwood, "Epigenetic Inactivation of Endothelin-1 And Endothelin-2 in Colon Cancer," International Journal of Cancer, Vol. 132, No. 5, 2013, pp. 1004-1012. doi:10.1002/ijc.27762

[4] L. G. Shack, A. Shah, P. C. Lambert and B. Rachet, "Cure by Age and Stage for Colorectal Cancer Patients in North West England, 1997-2004: A Population-Based Study," Cancer Epidemiology, Vol. 36, No. 6, 2013, pp. 548-553.

[5] R. R. Huxley, A. Ansary-Mogdahham, P. Clinton, S. Czernichow, C. L. Parr and M. Woodward, "The Impact of Dietary and Lifestyle Riskfactors on Risk of Colorectal Cancer: A Quantitative Overview of the Epidemiological Evidence," International Journal of Cancer, Vol. 125, No. 1, 2009, pp. 171-180. doi:10.1002/ijc.24343

[6] J. N. Poynter, S. B. Gruber, P. D. R. Higgins, R. Almog, J. D. Bonner, H. S. Rennert, M. Low, J. K. Greenson and G. Rennert, "Statins and the Risk of Colorectal Cancer," New England Journal of Medicine, Vol. 352, No. 21, 2005, pp. 2184-2192.

[7] M. R. Schweiger, M, Husoong, C, Rohr and H. Lehrach, "Genomics and Epigenomics of Colorectal Cancer," Wiley Interdisciplinary Reviews: Systems Biology and Medicine, Vol. 5, No. 2, 2013, pp. 205-219.

[8] L. Yan, E. L. Spitznagel and M. C. Bosland, "Soy Consumption and Colorectal Cancer Risk In Humans: A MetaAnalysis," Cancer Epidemiology Biomarkers Prevention, Vol. 19, No. 1, 2010, pp. 148-158. doi:10.1158/1055-9965.EPI-09-0856

[9] G. Yang, X. O. Shu, H. Li, W. H. Chow, H. Cai, X. Zhang, Y. T. Gao and W. Zheng, "Prospective Cohort Study of Soy Food Intake and Colorectal Cancer Risk in Women," American Journal of Clinical Nutrition, Vol. 89, No. 2, 2009, pp. 577-583. doi:10.3945/ajcn.2008.26742

[10] A. F. Galvez and B. O. de Lumen, "A Soybean cDNA Encoding a Chromatin-Binding Peptide Inhibits Mitosis of Mammalian Cells," Nature Biotechnology, Vol. 17, No. 5, 1999, pp. 495-500.

[11] H. J. Jeong, Y. Lam and B. O. de Lumen, "Barley Lunasin Suppresses Ras-Induced Colony Formation and Inhibits Core Histone Acetylation in Mammalian Cells," Journal of Agricultural and Food Chemistry, Vol. 50, No. 21, 2002, pp. 5903-5908.

[12] J. B. Jeong, H. J. Jeong, J. H. Park, S. H. Lee, J. R. Lee, H. K. Lee, G. Y. Chung and B. O. de Lumen, "CancerPreventive Peptide Lunasin from Solanum nigrum L. Inhibits Acetylation of Core Histones $\mathrm{H} 3$ and $\mathrm{H} 4$ and Phosphorylation or Retinoblastoma Protein (Rb)," Journal of Agricultural and Food Chemistry, Vol. 55, No. 26, 2007, pp. 10707-10713. doi:10.1021/if072363p

[13] H. J. Jeong, J. B. Jeong, D. S. Kim, J. O. Park, J. B. Lee, D. H. Kweon, G. Y. Chung, E. W. Seo and B. O. de Lumen, "The Cancer Preventive Peptide Lunasin from Wheat Inhibits Core Histone Acetylation," Cancer Letters, Vol. 255, No. 1, 2007, pp. 42-48. doi:10.1016/j.canlet.2007.03.022

[14] G. G. Meadows, "Diet, Nutrients, Phytochemicals, and Cancer Metastasis Suppressor Genes," Cancer Metastasis Reviews, Vol. 31, No. 3-4, 2012, pp. 441-454. doi:10.1007/s10555-012-9369-5

[15] B. Hernandez-Ledesma, C. C. Hsieh and B. O. de Lumen, "Relationships between Lunasin Sequence and Its Inhibitory Activity of Histones H3 and H4," Molecular Nutrition and Food Research, Vol. 55, No. 7, 2011, pp. 989998. doi:10.1002/mnfr.201000632

[16] V. P. Dia and E. G. de Mejia, "Lunasin Promotes Apoptosis in Human Colon Cancer Cells by Mitochondrial Pathway Activation and Induction of Nuclear Clusterin Expression," Cancer Letters, Vol. 295, No. 1, 2010, pp. 
426-430.

[17] V. P. Dia and E. G. de Mejia, "Lunasin Potentiates the Effect of Oxaliplatin Preventing Outgrowth of Colon Cancer Metastasis, Binds to Alpha 5 Beta 1 Integrin and Suppresses FAK/ERK/NF-Kappa B Signaling," Cancer Letters, Vol. 313, No. 2, 2011, pp. 167-180. doi:10.1016/i.canlet.2011.09.002

[18] K. Morikawa, S. M. Walker, M. Nakajima, S. Pathak and I. J. Fidler, "Influence of Organ Environment on the Growth, Selection and Metastasis of Human Colon Carcinoma Cell In Nude Mice," Cancer Research, Vol. 49, No, 23, 1988, pp. 6863-6871.

[19] A. Cavazos, E. M. Morales, V. P. Dia and E. G. de Mejia, "Analysis of Lunasin in Commercial and Pilot Plant Produced Soybean Products and an Improved Method of Lunasin Purification," Journal of Food Science, Vol. 77, No. 5, 2012, pp. C539-C545. doi:10.1111/j.1750-3841.2012.02676.x

[20] I. G. Zubeldia, A. M. Bleau, M. Redrado, D. Serrana, A. Agliano, C. Gil-Puig, F. Vinal-Vanaclocha, J. Lecanda and A. Calvo, "Epithelial to Mesenchymal Transition and Cancer Stem Cell Phenotypes Leading to Metastasis Are Abrogated by the Novel TGF-Beta-1 Peptides P17 and P144," Experimental Cell Research, Vol. 319, No, 2013, pp. 12-22.

[21] A. F. Galvez, N. Chen, J. Macasieb and B. O. de Lumen, "Chemopreventive Property of a Soybean Peptide (Lunasin) That Binds to Deacetylated Histones and Inhibits Acetylation," Cancer Research, Vol. 61, No. 20, 2001, pp. 7473-7478.

[22] C. C. Hsieh, B. Hernandez-Ledesma, H. J. Jeong, J. H. Park and B. O. de Lumen, "Complementary Roles in Cancer Prevention: Protease Inhibitor Makes the Cancer Preventive Peptide Lunasin Bioavailable," Plos One, Vol. 5, No. 1, 2010, Article ID: e8890.

[23] C. C. Hsieh, B. Hernandez-Ledesma and B. O. de Lumen, "Soybean Peptide Lunasin Suppresses in Vitro and in Vivo 7,12-Dimethylbenz-[a]Anthracene-Induced Tumorigenesis," Journal of Food Science, Vol. 75, No. 9, 2010, pp. H311-H316. doi:10.1111/j.1750-3841.2010.01861.x

[24] S. N. Narzhny, "Proliferating Cell Nuclear Antigen: A Proteomic View," Cellular and Molecular Life Sciences, Vol. 65, No, 23, 2008, pp. 3789-3808. doi:10.1007/s00018-008-8305-x

[25] S. Eltz, E. Comperat, O. Cussenot and M. Roupret, "Molecular and Histological Markers in Urothelial Carcinomas of the Upper Urinary Tract," BJU International, Vol. 102, No. 5, 2008, pp. 532-535.

[26] W. Zhong, J. Peng, H. He, D. Wu, Z. Han, X. Bi and Q.
Dai, "Ki-67 and PCNA Expression in Prostate Cancer and Benign Prostatic Hyperplasia," Clinical Investigations in Medicine, Vol. 31, No. 1, 2008, pp. E8-E15.

[27] Z. Tan, M. Wortman, K. L. Dillehay, W. L. Seibel, C. R. Evelyn, S. J. Smith, L. H. Malkas, Y. Zheng, S. Lu and Z. Dong, "Small-Molecule Targeting of Proliferating Cell Nuclear Antigen Chromatin Association Inhibits Tumor Cell Growth," Molecular Pharmacology. Vol. 81, No. 6, 2012, pp. 811-819. doi:10.1124/mol.112.077735

[28] X. Z. Guo, X. D. Shao, M. P. Liu, J. H. Xu, L. N. Ren, J. J. Zhao, H. Y. Li and D. Wang, "Effect of bax, bcl-2 and bcl-xL on Regulating Apoptosis in Normal Liver and Hepatocellular Carcinoma," World Journal of Gastroenterology, Vol. 8, No, 6, 2002, pp. 1059-1062.

[29] B. Hrenandez-Ledesma, C. C. Hsieh and B. O. de Lumen, "Lunasin, a Novel Seed Peptide for Cancer Prevention," Peptides, Vol. 30, No. 2, 2009, pp. 426-430. doi:10.1016/j.peptides.2008.11.002

[30] V. P. Dia, S. Torres, B. O. de Lumen, J. W. Erdman and E. G. de Mejia, "Presence of Lunasin in Plasma of Young Men after Soy Protein Consumption," Journal of Agricultural Food Chemistry, Vol. 57, No. 4, pp. 1260-1266.

[31] H. M. Collins, M. K. Abdelghany, M. Messmer, B. Yue, S. E. Deeves, K. B. Kindle, K. MAntelingu, A. Aslam, G. S. Winkler, T. K. Kundu and D. M. Heery, "Differential Effects of Garcinol and Curcumin on Histone and p53 Modifications in Tumour Cells," BMC Cancer, Vol. 13, 2013, Article ID: 37. doi:10.1186/1471-2407-13-37

[32] Y. Wang and Y. Shang, "Epigenetic Control of Epithelial-to-Mesenchymal Transition and Cancer Metastasis," Experimental Cell Research, Vol. 319, No. 2, 2013, pp. 160169. doi:10.1016/i.yexcr.2012.07.019

[33] J. S. Lee, E. Smith and A. Shilatifard, "The Language of Histone Crosstalk," Cell, Vol. 142, No. 5, 2010, pp. 682685. doi:10.1016/j.cell.2010.08.011

[34] R. MArmorstein and S. Y. Roth, "Histone Acetyltransferase: Function, Structure, and Catalysis," Current Opinion in Genetic Development, Vol. 11, No. 2, 2001, pp. 155-161.

[35] Q. Li and H. Chen, "Epigenetic Modifications of Metastasis Suppressor Genes in Colon Cancer Metastasis," Epigenetics, Vol. 6, No. 7, 2011, pp. 849-852. doi:10.4161/epi.6.7.16314

[36] S. C. Truant, V. P. Gouyer, E. A. Leteurte, F. Zerimech, G. M. Huet and F. R. Pruvot, "E-Cadherin and BetaCatenin mRNA Levels throughout Colon Cancer Progression," Journal of Surgical Research, Vol. 150, No. 2, 2008, pp. 212-218. doi:10.1016/i.jss.2007.12.800 